How to Cite

Espique, F. P. (2018). Learners' performance in science using pangasinense as a language of instruction. International Journal of

Humanities, Literature \& Arts, 1(1), 31-37. https://doi.org/10.31295/ijhla.v1n1.31

\title{
Learners' Performance in Science using Pangasinense as a Language of Instruction
}

\author{
Felina P. Espique \\ Faculty of the School of Teacher Education and Liberal Arts Saint Louis University, Baguio City \\ Email:ngolab.jherlanie@gmail.com
}

\begin{abstract}
The shifting of language as a medium of instruction in Philippine schools has significant effects on the learning performance of the students. Grade 1 to 3 used Mother as their medium of instruction by the time they reach grade 4, the language of instruction will shift to English. This paper aims to further analyze if shifting is something to consider as positive. Mixed-method design specifically explanatory sequential design was used to collect and analyze quantitative data through an examination and then obtained qualitative data through interviews. A Likert scale was used to reveal that there is no significant difference in the performance of the pupils who used Pangasinense and English as a medium of Instruction. Since most of the results were interpreted as a beginning, it evidently shows that the pupils at this level struggle with their competency; prerequisite and fundamental knowledge and skills have not been acquired or developed adequately. Therefore, the shifting then of the language can affect the learning ability of the student but not the language itself.
\end{abstract}

Keywords---instruction language, pangasinense.

\section{Introduction}

The varied cultural identity of the Philippines affirmed colossal language distinctiveness within the region was a major obstacle to language policy in education (Burton, 2013). The Philippine with a Hundred of languages yielded multiple dilemmas for fulfilling a national language policy, thus the implementation ultimately required competent and genuine guidelines to fulfill the desired outcome and produce consummate quality output. Consequently, the multilingual condition of the country propelled the Philippines to extremely excel in the Global performance in terms of Academic and business English which opened the Filipino community to travel and work which also became a magnet to the international community to engage business and education as well (Wa-Mbaleka, 2014).

Mother tongue is a language a child learns primarily before he learns second languages in the learning institutions. In November 2013, the $4^{\text {th }}$ International Conference on Language and Education conveyed that MTBMLE is not just about the materials, the programs to be initiated or the language itself but talks about the wider scope of skills and concentrates on critical thinking as well. It is also about highlighting the means and ways of students in their manner of learning or acquiring knowledge amid a dynamic learning environment.

In the year of 1974 Bilingual Education policy classified two major languages, Filipino and English as a language of instruction in the entire schools of the region, however dominantly the entire population have no idea about the language. The agreement to incorporate the framework of this language was inspired by the idea that English is the language of success (Garbes, 2012). However the integration of this idea can potentially harm cultural identity, students will condition their mindset to embrace English and prospect their native language as insignificant. In 2003 the Functional Literary Education and Mass Media Statistics (FLEMMS) reported that among the 57.59 million with an average age of 10-65 year old, more than 5 million cannot read and write, more than 7 million cannot read, write and compute while more than 18 million cannot read, write, compute and comprehend. This literacy rate census primarily attributed the language of instruction practiced inside the schools is a primary variable to determine academic performance (Wendisprinda, 2014).

The language of Instruction is now a vital and critical discussion of its ultimate contribution to the academic proficiency of student's capacity to perform. Numerous researchers conclude that children often acquire the second

ISSN 2632-9441

Received Jan 10, 2018 / Accepted Jun 20, 2018 / Published Jul 05, 2018 
language (L2) better if the first language (L1) was profoundly learned before proceeding to the acquisition of the second language. Although there are challenges for bilingual learners as to what mother tongue they would learn in relation to the locality they are residing in. Due to erratic economic conditions, most people decide to move to a more beneficial place that will provide them more opportunities. As a result of this, not only regional borders are crossed but linguistic borders as well. Because of these endeavors, the competence of the learners can be influenced and will be more complex (Wa-Mbaleka, 2014).

In a research involving five six-year-old Turkish children living in Germany and in Turkey, had scored higher points in a test about mother tongue and also garnered higher points in reading-readiness. Therefore, readingreadiness is remarkable if they have a higher level of competency in mother tongue, regardless if the learner is bilingual or monolingual. The research study, therefore, recommended not only to parents but the use of mother tongue as a medium of instruction in teaching.

An elementary science group of NISMED in 2003 conducted a research on the circulatory system, proposed the use of a language that the pupils are familiar with, in order to promote active participation in class. It was given an account that the children were able to express themselves confidently when they made use of Filipino in their intervention activities which showed that they have developed their self-esteem and showed enthusiasm during the activity. Thus, in learning the concept of circulatory system, such positive experiences contributed to a successful learning process (Reyes, 2010).

In relation to this, in the introduction of Natural Sciences at Grade 4 when the medium of instruction shifted from mother tongue to English, it was presumed that there will be a problem in their academic performance and confidence in this subject. Because of this, IsiXhosa a mother tongue in Africa was visualized to retain as a medium of instruction in Science for another 3 years so that it would improve the level of understanding of the learners and their confidence in science. Through the acquiescence of IsiXhosa as a medium of instruction, African parents would be able to help and assist their children in their assignments or school works because they know something or that they are familiar with the language. Moreover, it would boost their self-confidence and strengthen their connection with their language and cultural identity as well. A learner's mother tongue is the foundation before learning the language (Alexander, 2003; Prah, 2003; Skutnabb-Kangas \& Garcia, 1995). Because of this, it was hypothesized that the learners would learn other languages easily if they acquired basic language skills in mother tongue as applied in the science subject. Another assumption is that the teacher would be more efficient in teaching the science subject if IsiXhosa or the mother tongue is used as a medium of instruction because it is more accessible to them (Desay, 2007).

These circumstances encouraged the Department of Education to adopt and craft a policy which will address the challenges faced in the implementation of the said policy. DepEd Order No. 16, series of 2012 mandates that starting school year (SY) 2012-2013, the Mother-Tongue-Based-Multilingual Education (MTB-MLE) shall be implemented in all public schools, specifically in Kindergarten, Grades 1, 2 and 3 as part of the $\mathrm{K}$ to 12 Basic Education Program which was further reinforced by R.A 105331 section 4 stating that for kindergarten and the first three (3) years of elementary education, instruction, teaching materials and assessment shall be in the regional or native language of the learners. The department shall also formulate a mother language transition program from grade 4 to grade 6 so that Filipino and English shall be gradually introduced as languages of instruction until such time when these two (2) languages can become the primary languages of instruction at the secondary level. The DepED identified 12 major languages; Hiligaynon, Waray, Ilocano, Chavacano, Pangasinense, Cebuano, Tausog, Tagalog, Kapampangan, Maranao, Maguindanaoan (DepEd, 2012).

In consideration of the above-cited literature and concerns in the use of mother tongue as a language of instruction, the aim of this study is to explore the level of performance in the content courses particularly in Science of the pupils who were taught using Pangasinense.

\section{Settings and Participants}

The study was conducted in the province of Pangasinan specifically in the City of Dagupan. This study targeted the performance of grade 4 pupils with ages ranging from 8-10 years old whose language of instructions in learning content subjects are Pangasinense and English. The participants came from Salapingao Elementary School and Lingayen 1 Central Elementary School. Salapingao Elementary School is located at 33 Salapingao Street, Salapingao District, Dagupan City, Pangasinan, they utilized Pangasinan as their medium of instruction in teaching content subjects while the elementary school of Lingayen 1 Central located at District 1 Lingayen Alvear Street west, Poblacion Lingayen, Pangasinan exercised English as their primary language of instruction in teaching content 
subject as well. Out of approximately 100 pupils of the entire population of the different schools, we selected 71 Grade Four pupils from both schools.

\section{Research Method}

This study utilized mixed-method design specifically explanatory sequential design. In an explanatory sequential design, the researcher first collects and analyzes quantitative data and then obtains qualitative data to follow up and refine the quantitative findings (Creswell, 2002). In this research, the level of competencies of the pupils was gathered and analyzed quantitatively. After which, the qualitative data gathered through focus group interviews were used to refine the quantitative findings.

\section{Data Gathering Tool}

For the quantitative part of the research study, a fifty (50) item examination following the Table of Specifications (TOS) in testing science competencies for grade four was utilized in this study. The items were taken from standardized tests that were provided by the Department of Education.

The tool that was utilized to gather the qualitative data was an interview guide. This was administered through focus group discussion or individual interview with the teachers. This was crafted after the quantitative data will be collected and analyzed. Prior to the interview phase, the results of the quantitative data collection and analysis were studied to help shape the qualitative research questions, sampling and data collection (Creswell, 2012).

A tape recorder was utilized in the conduct of the interview since it is often considered an indispensable part of any qualitative researcher's equipment. Using a tape recorder, however, does not eliminate the need for taking notes (Fraenkel \& Wallen, 2006).

\section{Data Gathering Procedure}

At the initial phase, letters of request addressed to the heads of offices concerned and to the respondents were given. With the permission of the offices and the willingness of the participants involved, administration of the test questions was scheduled. The administration of the test questions to the student teacher respondents was done personally by the researchers to ensure gathering of appropriate data. After the data has been gathered, these were subjected to statistical treatment with the help of recognized statisticians by the Research and Extension Office (REO) of the Saint Louis University, Baguio City. The quantitative results were utilized to develop the qualitative research questions that were based on dubious results as shown by the quantitative data that was called for further clarification and confirmation. These were identified by the researchers themselves.

After the framing and validation of the research questions by a selected panel of examinees, the identification of the target participants from the group of teacher respondents for the gathering of the qualitative data followed next. After which, the focus group interviews were scheduled based on the availability of the respondents. To elicit more natural responses to the problem, all the respondents were interviewed in locations of their own choice, on the assumption that they would be more comfortable in a familiar environment. Respondents were guaranteed of anonymity and were told that they could refuse to answer any question or stop the interview at any time, and that participation is exclusively voluntary (Fraenkel \& Wallen, 2006). Before conducting the focus group interviews, the purpose and design of the study were presented to assure that everyone would receive consistent orientation. Audio recordings were done during interviews with the permission of the respondents. The recorded conversations were transcribed accurately and were cleansed from "transfer error" through corrective listening (Flick et al., 2004).

The transcribed result of the discussions and interviews were used to help explain the quantitative results that need further exploration and to answer new questions that emerged from the quantitative results (Creswell, 2012).

\section{Treatment of the Data}

To be able to know the level of competencies of the pupils, the raw scores were converted into percentages and the following level of competency was employed: 
Table 1

The level of competencies of the pupils

\begin{tabular}{ll}
\hline Level of Competency & Equivalent Numerical Value \\
\hline Beginning & $74 \%$ and below \\
Developing & $75 \%-79 \%$ \\
Approaching Competency & $80 \%-84 \%$ \\
Proficient & $85 \%-89 \%$ \\
Advanced & $90 \%$ and above \\
\hline
\end{tabular}

The competency level of the language student teachers shall be described based on the following:

a) Beginning - The student teacher at this level struggles with his/her competency; prerequisite and fundamental knowledge and/or skills have not been acquired or developed adequately.

b) Developing - The student teacher at this level possesses the minimum knowledge and skills and core competencies but needs help throughout the accumulation of competencies.

c) Approaching Competency - The student teacher at this level has developed the fundamental knowledge and skills and core competencies and, with little guidance and assistance, can perform the competencies.

d) Proficient - The student teacher at this level has developed the fundamental knowledge and skills and core competencies and can perform them independently.

e) Advanced - The student teacher at this level exceeds the core requirements in terms of knowledge, skills, and competencies, and can perform them automatically and flexible.

In the treatment of the qualitative data, significant statements of the respondents helped clarify dubious results in the quantitative data was filtered. To identify the significance statements, frequency or common statements were considered. After which, these statements were used in the results and discussion part to clarify, substantiate, and confirmed the outcome of the quantitative results.

The language training program that will be designed was based on the results and discussions done. The program will focus on the enhancement of the competencies that got the lowest level.

\section{Results and Analysis}

This portion is the collection of data's presented, analyzed and interpreted. The first part presents the result and discussions of the quantitative and qualitative phase. The data are presented in a table whereas it was divided into three major columns consisting of the topics, mean percentage and the qualitative interpretation of the mean percentage of both English and Mother tongue group.

Table 2

Mean percentage and the qualitative interpretation

Quantitative Analysis

\begin{tabular}{|c|c|c|c|c|c|}
\hline & & & lish & & Tongue \\
\hline & Topic & Mean & Qualitative & Mean & Qualitative \\
\hline & & Percentage & Interpretation & Percentage & Interpretation \\
\hline Matter & - Properties & $73 \%$ & Beginning & $38 \%$ & Beginning \\
\hline & - Changes That & $74 \%$ & Beginning & $49 \%$ & Beginning \\
\hline & Materials & & & & \\
\hline & Undergo & & & & \\
\hline Living Things & - Humans & $71 \%$ & Beginning & $30 \%$ & Beginning \\
\hline and Their & - Animals & $79 \%$ & Developing & $40 \%$ & Beginning \\
\hline Environment & - Plants & $62 \%$ & Beginning & $48 \%$ & Beginning \\
\hline & - Heredity & $64 \%$ & Beginning & $60 \%$ & Beginning \\
\hline Force and & - Effects & $72 \%$ & Beginning & $36 \%$ & Beginning \\
\hline
\end{tabular}




\begin{tabular}{cccccc} 
Matter & $\bullet$ Light & $50 \%$ & Beginning & $22 \%$ & Beginning \\
& Total & $68 \%$ & Beginning & $40 \%$ & Beginning \\
\hline
\end{tabular}

The first table of the first column is the general topics, followed by the subtopics under the K12 curriculum for grade 4 from $1^{\text {st }}$ quarter to $3^{\text {rd }}$ quarter with which the students will gain and exercise their knowledge. The third column comprises the mean percentage of the scores garnered by the pupils who were taught Science using the English Language next to the qualitative interpretation of the numerical values. The fourth and fifth column contains the mean percentage of the scores obtained by the pupils who were taught Science using Pangasinense alongside the qualitative interpretation of the said percentage.

The pupils who were taught Science using the English language excelled in the area of Living Things and their Environment specifically under the subtopic Animals, they accumulated a mean percentage of $79 \%$ as the highest score which is interpreted as developing, this tells us that the pupils at this level possesses the minimum knowledge and skills and core competencies, but needs help throughout the accumulation of competencies, while they scored lowest on the topic Light under Force and Motion with a mean percentage of 62\% interpreted as Beginning. It evidently shows that the pupils at this level struggle with his/her competency; prerequisite and fundamental knowledge and/or skills have not been acquired or developed adequately. On the contrary, the pupils who were taught Science using Pangasinense did well on the topic Heredity under Living things and Their Environment with a mean percentage of $60 \%$ as the highest percentage among all the score. This is interpreted as Beginning, the pupils at this level struggle with his/her competency; prerequisite and fundamental knowledge and/or skills have not been acquired or developed adequately. Their lowest mean score is $22 \%$ under the subtopic Light under Force and Matter which was the lowest as well. This is interpreted as the beginning. The pupils at this level struggle with his/her competency; prerequisite and fundamental knowledge and/or skills have not been acquired or developed adequately.

The numerical gap between the mean percentages by the pupils who were taught using English and Pangasinense will explain to us that there is a significant difference in their performance, because the language of the exam which is English is efficient to the English group since they have adopted the language and excelled in the familiarity of the subject matter, consequently the mother tongue group who took the exam using the English language had a hard time understanding the examination itself since they are used to Pangasinan as their medium of instruction in understanding the subject.

Ironically, as shown in the table in the qualitative interpretation of mother tongue and English both fall under the beginning level based on the Likert scale will generally tell us there is no significant difference in the performance of both English and mother tongue group in science.

In general, there is no significant difference in the learning performance of students who were taught English and Pangasinense as a medium of instruction.

The result is influenced by some several factors. The mother tongue based education of the $\mathrm{k} 12$ program of the government instituted in 2013 is a fresh and new concept introduced to the educational system of the country. Thus the educational system of the country is progressively adjusting to adapt and gradually synchronize to the changes.

A teacher tells "Since the first year of implementation... na ngangapa pa"

Moreover, the scarcity of books and learning materials consequently resulted to the inability of students and teachers to access auxiliary information to support the process of teaching and learning which added loads of difficulty.

"we can't further explain the topics in an easy way that pupils can understand because of lack of books, facilities or equipment like projectors, laptop and other and because we are in island barangay the internet access very low."

Resources to support the process of teaching are a springboard to elevate student's competence. But their facilities produce minimal force to partake in the welfare and development of their students.

A teacher cannot teach proficiently without appropriate materials that are based on two components: established government curriculum goals and pupil's prior knowledge, culture and value system (Hall, 2010; Dekker et al., 2008).

Provided with few books available for most of the 170 languages that are found here in the Philippines, the development of materials appears to be a daunting task (Dekker et.al). 2 or $16.67 \%$ of the total number of respondents say that all they need are textbooks and dictionaries which are in Mother Tongue to accommodate their needs in their learning process since they have different Mother tongue while 10 or $83.33 \%$ of the respondents answered contrary (Brillo et al., 2016).

Books are very essential in the learning process of the pupils since the teaching-learning process is not really effective without the use of appropriate and adequate instructional materials. (Grant, 1978 Sunday and Joshua) 
Moreover, Inadequate training to cultivate the teachers increase the range of their competence to teach mother tongue will result in poor teaching. A teacher said

"insufficient knowledge/ training of teachers teaching the subject using mother tongue"

Teacher necessarily needs plentiful schooling and training to acquire stimulation. Since it would be a venue for them to advance their abilities and broaden their knowledge of mother tongue.

The Alliance of Concerned Teachers (ACT) secretary general France Castro said that the time spent for teacher's training is not enough. A part of $\mathrm{k}$ to 12 program's implementation is the training for public schools' teachers. However, it was noted by the teachers themselves who have undergone these training said that these training are rushed and not well thought of. In addition, Mr. Castro stated that "there are lots of new things for teachers to learn in order to implement the new curriculum. One to two months training is not enough" (Umil \& Viray, 2012).

For the reason that students complained they find it difficult to follow their teacher because of inadequate example to reinforce the topic.

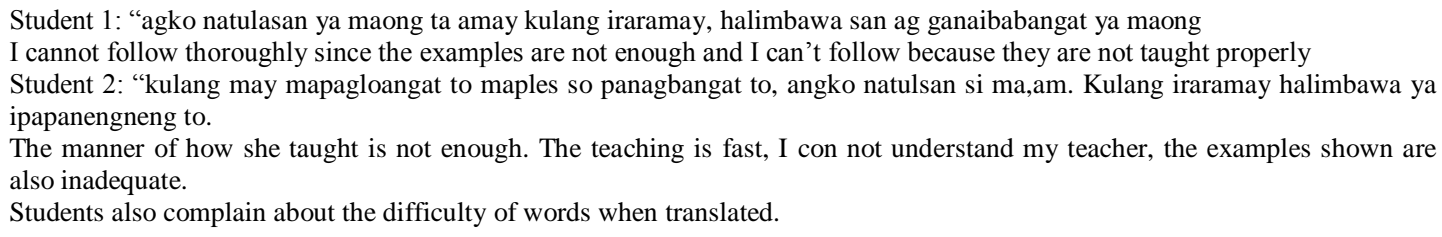

One of the prevalent problems among the teachers was having difficulty in translating a target language which is English into mother tongue because teachers lack vocabulary and reference materials like textbooks and dictionaries which are essential to delivering the lessons effectively. 8 or $66.67 \%$ out of the total number of the respondents answered that they have problems in translating the target language to mother tongue while 4 or $33.33 \%$ of the total respondents answered the opposite. In the usage of the mother tongue, translation is very beneficial because it serves as a bridge that connects the pupils or the learners to the lesson (Brillo et al., 2016).

\section{Conclusion}

In general, there is no significant difference in the learning performance of students who were taught English and Pangasinense as a medium of instruction. Base on the results of this study either/whether English or mother tongue was used in teaching science it will not affect the performance of the students. The shifting then of the language can affect the learning ability of the students but not the language itself.

\section{Recommendation}

Since the k12 program is a law which could no longer be revised, we as a group in this study recommend that the Department of education in the government of the Philippines has to be serious to address the flaws of the circumstances and should provide sufficient trainings for teachers and the improvements of materials or educational resources such as books that are supposed to be in mother tongue to further support the implementation of the k12 curriculum for a more productive learning course for Filipino learners.

\section{Acknowledgements}

The author would like to thank the editor for their valuable time and advice. 


\section{References}

Annetta, L. A., Minogue, J., Holmes, S. Y., \& Cheng, M. T. (2009). Investigating the impact of video games on high school students' engagement and learning about genetics. Computers \& Education, 53(1), 74-85.

Astawa, I. N., Handayani, N. D., Mantra, I. B. N., \& Wardana, I. K. (2017). Writing English Language Test Items as a Learning Device: A Principle of Habit Formation Rules. International Journal of Social Sciences and Humanities (IJSSH), 1(3), 135-144.

Astawa, I. N., Mantra, I. B. N., \& Widiastuti, I. A. M. S. (2017). Developing Communicative English Language Tests for Tourism Vocational High School Students. International Journal of Social Sciences and Humanities (IJSSH), 1(2), 58-64.

Ball, J. (2010). Enhancing learning of children from diverse language backgrounds: Mother tongue-based bilingual or multilingual education in early childhood and early primary school years. Victoria, Canada: Early Childhood Development Intercultural Partnerships, University of Victoria.

Brillo, J. (2016). Thermophysical properties of multicomponent liquid alloys. Walter de Gruyter GmbH \& Co KG.

Burton, L. A. (2013). Mother tongue-based multilingual education in the Philippines: Studying top-down policy implementation from the bottom up. University of Minnesota.

Creswell, J. W. (2002). Educational research: Planning, conducting, and evaluating quantitative (pp. 146-166). Upper Saddle River, NJ: Prentice Hall.

Dep. Ed. (2012). Guidelines on the Implementation of the Mother Tongue-Based- Multilingual Education (MTBMLE) . Dep Ed order no. 16.

Dep. Ed. (2012). Policy Guidelines on the Implementation of Grades 1 to 10 of the $\mathrm{K}$ to 12 Basic Education Curriculum (BEC) Effective School Year 2012-2013 . Dep Ed order no. 31.

Garbes, L., Heesen, L., Hölker, I., Bauer, T., Schreml, J., Zimmermann, K., ... \& Brüstle, O. (2012). VPA response in SMA is suppressed by the fatty acid translocase CD36. Human molecular genetics, 22(2), 398-407.

Graveley, B. R., Brooks, A. N., Carlson, J. W., Duff, M. O., Landolin, J. M., Yang, L., ... \& Brown, J. B. (2011). The developmental transcriptome of Drosophila melanogaster. Nature, 471(7339), 473.

Malone, S. (2007, September). Mother tongue-based multilingual education: Implications for education policy. In Seminar on Education Policy and the Right to Education: Towards More Equitable Outcomes for South Asia's Children (2007 Kathmandu).

Mohanty, A. K. (2006). Multilingualism of the unequals and predicaments of education in India: Mother tongue or other tongue. Imagining multilingual schools, 262-283.

Nomlomo, V. S. (2007). Science teaching and learning through the medium of English and IsiXhosa: A Comparative study in two primary schools in the Western Cape (Doctoral dissertation, University of the Western Cape).

Olanipekun, S. S., Atteh, D., Andokari, J., \& Sarki, P. E. (2014). Mother tongue and students' academic performance in English language among secondary school students. International Journal of Language, Literature and Culture, $1(1), 1$.

Rosell, R., Carcereny, E., Gervais, R., Vergnenegre, A., Massuti, B., Felip, E., ... \& Porta, R. (2012). Erlotinib versus standard chemotherapy as first-line treatment for European patients with advanced EGFR mutation-positive nonsmall-cell lung cancer (EURTAC): a multicentre, open-label, randomised phase 3 trial. The lancet oncology, 13(3), 239-246.

Suparsa, I. N., Mantra, I. B. N., \& Widiastuti, I. A. M. S. (2017). Developing Learning Methods of Indonesian as a Foreign Language. International Journal of Social Sciences and Humanities (IJSSH), 1(2), 51-57.

Suryasa, I. W., Prayoga, I. G. P. A., \& Werdistira, I. W. A. (2017). An Analysis of Students' Motivation Toward English Learning As Second Language Among Students In Pritchard English Academy (PEACE). International Journal of Social Sciences and Humanities (IJSSH), 1(2), 43-50.

Umil, A. and Viray, P. (2012). "Rushed trainings, lack of materials mar implementation of K to 12".

Wa-Mbaleka, S. (2015). Switching to Mother Tongue-Based Education: The New Trend and Its Challenges. USChina Foreign Language, 257. 